\title{
Walter Obermaier, Orpheus in der Unterwelt. Text und Aufführung unter Mitwirkung Johann Nestroys
}

\section{Marc Lacheny}

\section{CpenEdition}

\section{Journals}

Édition électronique

URL : https://journals.openedition.org/austriaca/915

DOI : 10.4000/austriaca.915

ISSN : 2729-0603

Éditeur

Presses universitaires de Rouen et du Havre

\section{Édition imprimée}

Date de publication : 1 décembre 2019

Pagination : 279-281

ISBN : 979-10-240-1454-8

ISSN : 0396-4590

\section{Référence électronique}

Marc Lacheny, « Walter Obermaier, Orpheus in der Unterwelt. Text und Aufführung unter Mitwirkung Johann Nestroys », Austriaca [En ligne], 88-89 | 2019, mis en ligne le 01 juillet 2020, consulté le 24 octobre 2022. URL : http://journals.openedition.org/austriaca/915 ; DOI : https://doi.org/10.4000/ austriaca.915

Ce document a été généré automatiquement le 24 octobre 2022.

Tous droits réservés 


\title{
Walter Obermaier, Orpheus in der Unterwelt. Text und Aufführung unter Mitwirkung Johann Nestroys
}

\author{
Marc Lacheny
}

\section{RÉFÉRENCE}

Walter Obermaier (éd.), Orpheus in der Unterwelt. Text und Aufführung unter Mitwirkung Johann Nestroys, Vienne, Lehner, 2019, 216 p., ISBN : 978-3-9028-5015-7.

1 La première viennoise d'Orphée aux Enfers (Orpheus in der Unterwelt), le 17 mars 1860 au Carltheater, fut le dernier grand succès de Johann Nestroy comme directeur de ce théâtre (sa direction prit fin le 31 octobre 1860) et fut, simultanément, le premier événement marquant dans la réception d'offenbach à Vienne. Un certain nombre de critiques indiquèrent d'emblée que Nestroy avait adapté la version allemande du texte d'Offenbach produite par Ludwig Kalisch: deux manuscrits datés de 1859 font ainsi explicitement référence à une adaptation de Nestroy " pour les scènes autrichiennes " (für die österreichischen Bühnen, p. 57).

Dans son édition d'Orpheus in der Unterwelt, Walter Obermaier - bien connu pour ses travaux sur l'histoire littéraire et culturelle viennoise, en particulier sur le théâtre des faubourgs de Vienne, ainsi que pour sa participation à l'édition historico-critique des œuvres de Nestroy parue chez Jugend \& Volk puis chez Deuticke de 1977 à 2012 reproduit pour la première fois en intégralité aussi bien le texte attribué à Nestroy (p. 13-53) que le Zensurbuch (p. 89-127), tout en abordant la question des divergences que présente le manuscrit du Carltheater par rapport à ce Zensurbuch (p. 86-89) : comme souvent, la censure, ou plus exactement l'autocensure, porte sur les questions relatives à la religion, la politique et la morale. Ce sont en particulier les passages ayant trait à l'érotisme et aux bonnes mœurs qui ont été ici "atténués ", de même que les 
allusions éventuelles à la situation politique de l'époque ont été retirées du discours de Jupiter.

3 Un chapitre très documenté (p.128-140) traite de la distribution prestigieuse de la première ainsi que de la redistribution ultérieure de certains rôles importants. Ce chapitre fourmille d'informations souvent inédites sur la troupe du Carltheater, comme le couple Grobecker, Louis Grois, le besogneux Franz Gämmerler ou encore Wilhelm Knaack, spécialisé dans les rôles comiques, en particulier sur un pan longtemps négligé par la recherche sur le Wiener Vorstadttheater, considéré comme un théâtre d'hommes : le rôle joué par les comédiennes (Therese Braunecker-Schäfer, Katharina Herzog, Emma Zöllner, etc.). Il s'agit ici d'un complément fort utile aux recherches déjà entreprises en ce domaine par W. Edgar Yates.

4 Les préparatifs (délicats) de la première viennoise sous la houlette de Carl Treumann (p. 72-83) et la réception de celle-ci par la critique de l'époque (p.141-181) sont aussi largement documentés, au même titre que les représentations qui ont suivi, et ce jusqu'à la mort de Nestroy, dans la mesure où l'œuvre d'Offenbach est restée au programme même lors des tournées du comédien-dramaturge en 1860 et 1861 au Kaitheater (p. 181-191). Globalement, la critique rend hommage aux décors de Moriz Lehmann mais se montre peu convaincue, voire franchement déçue par la prestation des comédiens, à l'exception de Nestroy, dont le jeu comique est unanimement salué (voir notamment p. 148 et 164). Dans une critique par ailleurs très précise, Friedrich Uhl, l'un des plus éminents feuilletonistes de son temps, souligne en revanche le vif succès remporté par la pièce auprès du public viennois (p. 167).

Enfin, un chapitre bref mais éclairant (p.197-201) s'applique à mettre en lumière la part que Nestroy a prise dans l'établissement du texte allemand qui a été joué au Carltheater. La conclusion de Walter Obermaier est que Nestroy n'a adapté de manière significative que le texte de son propre rôle, celui de Jupiter. La critique de l'époque a d'ailleurs elle-même considéré comme essentiel pour le succès de la pièce « der äußerst komische Dialog, den Nestroy-Jupiter sich selbst gemacht » (cité p. 171). Et Walter Obermaier de constater que les rares citations tirées des critiques qui proviennent clairement du Nestroy-Text concernent exclusivement son propre rôle et sont issues du deuxième acte se déroulant dans l'olympe, comme cette citation: "Nur den Schein bewahren, liebe Kinder. Denn wenn's Volk auch nur's Volk ist, so sind's doch am End' die Leut' und vor den Leuten heißt's immer den Nimbus bewahren » (cité p. 149). Du reste, de nombreux passages - comme presque tous les dialogues de Jupiter dans le deuxième acte de la pièce portent la marque de Nestroy, ainsi que le montre la comparaison avec le texte du Zensurbuch. Pour ce qui est des parties chantées, il est en revanche fort peu probable que Nestroy les ait retouchées: le Witz linguistique en est presque totalement absent. Comme le souligne Walter Obermaier, c'est sans doute Carl Treumann qui s'en est chargé (voir p. 200).

Orpheus in der Unterwelt, synonyme d'entrée de l'opérette à Vienne, constitue un document important témoignant de la relation créative de Nestroy avec ses sources (notamment françaises) et de la présence sur scène du comédien-dramaturge-directeur de théâtre au cours de ses dernières années de vie. 